TABLE I.

\begin{tabular}{ccccc}
\hline & \multicolumn{5}{c}{ Densities: $\mathrm{g}$ per cc } \\
Temp. ${ }^{\circ} \mathrm{C}$ & $\rho L$ obs & $\rho L$ calc & $\rho V$ obs & $\rho V$ calc \\
\hline 155.8 & 0.70520 & 0.7052 & 0.0079 & 0.00903 \\
173.3 & 0.67059 & 0.6705 & 0.012494 & 0.01241 \\
123.6 & 0.62478 & 0.6500 & 0.01587 & 0.01530 \\
198.9 & 0.61920 & 0.6192 & 0.02106 & 0.02120 \\
212.0 & 0.59305 & 0.5935 & 0.02775 & 0.02745 \\
232.4 & & & 0.04280 & 0.04255 \\
237.3 & 0.5359 & 0.5350 & & \\
244.6 & 0.51993 & 0.5202 & 0.05516 & 0.05400 \\
260.6 & 0.48589 & 0.4835 & 0.07733 & 0.07750 \\
268.9 & 0.45740 & 0.4570 & 0.09480 & 0.09520 \\
272.25 & 0.43200 & 0.4460 & 0.1023 & 0.1024 \\
276.45 & 0.42370 & 0.4205 & 0.1300 & 0.1270 \\
283.94 & 0.3620 & 0.3580 & 0.1681 & 0.1662 \\
285.72 & 0.3620 & 0.3220 & 0.2402 & 0.2220 \\
\hline
\end{tabular}

calibrated glass capillary containing the samples and enclosed in a constant temperature apparatus. Pressures were measured by a Barrett dead weight test gauge with calibrated piston diameters and weights. Temperatures were maintained by an atmosphere of pure organic vapors distilling at constant temperature, and were measured by copper-constantan thermocouples calibrated against a platinum resistance thermometer with an NBS certificate. For a series of specific temperatures, the pressures and volumes were read, the latter by using a cathetometer calibrated against a standard meter stick. Corrections for menisci, interphase levels, and ambient conditions were made. Corrections for expansion of the glass capillary due to pressure and temperature changes were made using the Bridgman equation ${ }^{2} \Delta V=V_{0}\left(30.27 \times 10^{-7} p\right.$ $+9.9 \times 10^{-12} p^{2}$ ) where $p=$ pressure in $\mathrm{Kgm} / \mathrm{cm}^{2}$, and a coefficient of cubical expansion of $9.9 \times 10^{-6} .^{3}$

The $n$-butanol (C.P. grade) was distilled at high reflux successively from calcium oxide, fresh magnesium, and activated alumina. Middle cuts were collected, and the final product gave a refractive index of 1.3973 at $25^{\circ} \mathrm{C}$ and a boiling point of $117.5^{\circ} \mathrm{C}$ at $760 \mathrm{~mm}$.

Densities for the saturated vapor and liquid are given in Table I. Equations for the saturated vapor and for the liquid densities have been determined as

$\rho_{V}=0.1424+0.44 \times 10^{-2} n+5.93125 \times 10^{-4} n^{2}$

and $+1.8408 \times 10^{-4} n^{3}+1.6317 \times 10^{-5} n^{4}$

$\rho_{L}=0.39718-0.005899 n-2.1212 \times 10^{-4} n^{2}$

$-1.48145 \times 10^{-4} n^{3}-2.3350 \times 10^{-5} n^{4}$

where $n=t^{\circ} \mathrm{C}-280.5^{\circ} \mathrm{C}$

In Table I observed values are experimentally determined, and calculated values were those obtained by the above equations and show a mean deviation of 0.15 percent for the liquid densities and 0.6 percent for the vapor densities. The critical density has been determined by the "law of rectilinear diameters," 4,5 and the equation for rectilinear diameters determined as

$d=0.28637-0.6165 \times 10^{-3} m+5.7986 \times 10^{-7} m^{2}$

$$
+5.324 \times 10^{-8} \mathrm{~m}^{3}+1.35732 \times 10^{-9} \mathrm{~m}^{4}
$$

where $m=t^{\circ} \mathrm{C}-250.0^{\circ} \mathrm{C}$. The critical constants were determined both analytically and graphically with excellent agreement, and

TABLE II.

\begin{tabular}{|c|c|c|c|c|}
\hline Date & $t_{\varepsilon}{ }^{\circ} \mathrm{C}$ & $p_{c}$ atmos & $\rho_{c} g / c c$ & Investigators \\
\hline 1883 & 287.1 & & & Pawlewski \\
\hline $\begin{array}{l}1884 \\
1923\end{array}$ & $\begin{array}{l}270.5 \\
287.0\end{array}$ & 48.4 & & $\begin{array}{l}\text { de Heen } \\
\text { Herz and Neukirche }\end{array}$ \\
\hline $\begin{array}{l}1943 \\
1955\end{array}$ & 288.0 & 48.60 & 02700 & Fischer and Reichel ${ }^{d}$ \\
\hline
\end{tabular}

a B. Pawlewski, Ber. deut. chem. Ges. 15, 2143, 2460 (1882).

b de Heen, Landolt, and Bornstein (Verlag Julius Springer, Berlin, 1923), Vol. 1 . P. 256.

c W. Herz and E. Neukirch, Z. Physik 104, 433 (1923).

d R. Fischer and T. Reichel, Mikrochimie 31, 192 (1943).

the results are shown, in comparison to other investigations, in Table II. It is considered that the critical temperature is accurate to $\pm 0.05^{\circ} \mathrm{C}$, the pressure to \pm 0.05 atmos and the density to $\pm 0.0002 \mathrm{~g}$ per cc. A more extensive report on the P-V-T relationships for $n$-butanol will be submitted for publication shortly.

Acknowledgments.--The assistance of R. W. Esplen and D. Clegg in making measurements, of W. Pye in glassblowing, and of the National Research Council of Canada in making a grant-in-aid is gratefully acknowledged.

* Demonstrator, Department of Chemical Engineering, University of British Columbia.

+ Associate Professor, Department of Chernical Engineering, University of British Columbia.

1 W. B. Kay, Ind. Eng. Chem. 24, 291 (1932).

3 Catal . Bridgman, Am. Sci. J. 7, 81 (1929).

$4 \mathrm{~L}$. Caillette and $\mathrm{E} 4$ Masies, Corning Glass Works, Corning

o. Y. Yung Sci. Proc. Roy. Dublin Soc. 12, 374, (1909-10).

\title{
Frequency Shift of the CO Stretching Band in Polypeptides and Proteins
}

SAMUEL KRIMM

Harrison M. Randall Laboratory of Physics, University of Michigan,
Ann Arbor, Michigan Ann Arbor, Michigan

(Received April 28, 1955)

T has been observed ${ }^{1,2}$ that the frequency of the CO stretching mode in synthetic polypeptides and natural proteins depends upon the configuration of the polypeptide chain: in the $\alpha$, or folded, form this frequency is close to $1660 \mathrm{~cm}^{-1}$, whereas in the $\beta$, or extended, form this frequency is close to $1630 \mathrm{~cm}^{-1}$. Although used as a means of distinguishing between $\alpha$ and $\beta$ forms of polypeptides and proteins, ${ }^{3}$ it does not appear that any explanation has been offered for the frequency shift. It is the purpose of this note to suggest a possible reason, one which seems to be supported by the presently available experimental evidence.

Although heretofore correlated with the $\alpha$ and $\beta$ configurations of the polypeptide chain, it is clear that the shift is more a reflection of the local environment of the $\mathrm{CO}$ group than it is of the over-all chain configuration. Such a change in environment would most naturally be related to the hydrogen bonding in which the $\mathrm{CO}$ group participates. Frequency shifts involving hydrogen bonding have been correlated with the distance between the atoms partaking in the hydrogen bond. ${ }^{4,5}$ This cannot, however, be the entire explanation in the present case, because the significant fact is that the NH stretching frequency does not shift by any appreciable amount from $\alpha$ to $\beta$ polypeptides, ${ }^{1}$ which it would be expected to do if the only result of the configurational change was a change in the $\mathrm{O} \cdots \mathrm{N}$ distance.

It is suggested that the frequency shift results from a configurational change in the $\mathrm{CO} \cdots \mathrm{NH}$ angle of the type schematically illustrated in I and II below. Assuming that the $\mathrm{O} \cdots \mathrm{H}$ force

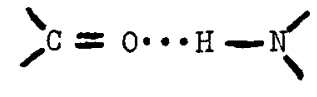

I

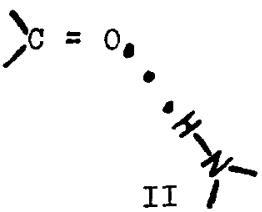

constant is essentially the same in I and II, it is clear that we would expect a relatively larger change in the $\mathrm{CO}$ frequency from I to II than in the NH frequency, since the CO force constant is more strongly affected. We would further expect that the $\mathrm{CO}$ frequency in I would be lower than in II. If the $\mathrm{H}$ atom were not along the $\mathrm{O} \cdots \mathrm{N}$ line, the result would be essentially the same, although the $\mathrm{NH}$ stretching frequency might undergo a small shift.

This explanation for the frequency shift seems to be consistent with the known structural features of present protein models and 
TABLE I. Correlation between $\mathrm{CO}$ stretching frequency and $\mathrm{CO} \cdots \mathrm{NH}$ angle.

\begin{tabular}{cccl}
\hline Substance & $\begin{array}{c}\text { CO } \cdots \mathrm{HN} \\
\text { angle }\end{array}$ & $\begin{array}{c}\text { CO stretching } \\
\text { frequency, } \\
\mathrm{cm}^{-1}\end{array}$ & References \\
\hline Silk & $\sim 180^{\circ}$ & 1640 & $\mathrm{~b} ;$ see footnote 3 \\
Nylon & $\sim 160^{\circ}$ & 1650 & $\mathrm{c} ; \mathrm{d}$ \\
Acetanilide & $145^{\circ}$ & 1660 & $\mathrm{e} ; \mathrm{f}$ \\
Urea & $180^{\circ}$ & 1680 & $\mathrm{~g} ; \mathrm{h}$ \\
Diketopiperazine & $\sim 120^{\circ}$ & 1705 & $\mathrm{i} ; \mathrm{j}$ \\
\hline
\end{tabular}

a But not colinear (see text).

b Marsh, Corey, and Pauling, Biochim. et Biophys. Acta 16, 1 (1955).

- Ambrose, Elliott, and Temple, Proc. Roy. Soc. (London) A199, 183 (1949).

d Elliott, Ambrose, and Temple, J. Chem. Phys. 16, 877 (1948).

f J. Mann and H. W. Thompson, Proc. Roy. Soc (London) A2i1, 168 (1952).

g P. A. Vaughan and J. Donohue, Acta Cryst. 5, 530 (1952).

h W. E. Keller, J. Chem. Phys, 16, 1003 (1948),

1 R. B. Corey, J. Am. Chem. Soc. 60,1598 (1938).

i Ambrose, Elliott, and Temple, Proc. Roy. Soc. (London) A206, 192 (1951).

of simple compounds. In Table I we present some results which correlate the CO $\cdots$ HN angle with the CO stretching frequency. It is seen that the relationship discussed above is well obeyed. The case of urea corresponds to structure II in which the $\mathrm{H}$ is not on the $\mathrm{O} \cdots \mathrm{N}$ line (but $\mathrm{CO}$ and $\mathrm{HN}$ bonds are parallel), and is seen to fit in well with the present explanation. The frequencies do not correlate as well with the hydrogen bond distances; e.g., $2.76 \mathrm{~A}$ in silk, $2.85 \mathrm{~A}$ in diketopiperazine, $2.97 \mathrm{~A}$ in acetanilide. In all cases the NH stretching frequency is close to $3300 \mathrm{~cm}^{-1}$, the value expected when hydrogen bonding occurs. Data on simple amides in solution and in the solid state ${ }^{6,7}$ are also in agreement with the above explanation: the more nearly colinear the CO $\cdots \mathrm{HN}$ hydrogen bond, the lower the $\mathrm{CO}$ stretching frequency. An accompanying shift in the $1530 \mathrm{~cm}^{-1}$ band $d^{1}$ from $\alpha$ to $\beta$ polypeptides is perhaps a result of the interaction between the $\mathrm{CO}$ frequency and the other modes of the peptide group. ${ }^{8}$

To the extent that the $\mathrm{CO}$ frequency is a measure of the $\mathrm{CO} \cdot \mathrm{HN}$ bonding angle, variations in this frequency would be indicative only of variations in the configuration of this hydrogen bond. It may not always be justifiable, therefore, to extrapolate from the value of this frequency to a particular polypeptide chain configuration.

1 E. J. Ambrose and A. Elliott, Proc. Roy. Soc. (London) A205, 47 (1951).

2 A. Elliott, Proc. Roy. Soc. (London) A221, 104 (1953).

3 E. J. Ambrose and A. Elliott, Proc. Roy. Soc. (London) A206, 206 (1951)

4 R. E. Rundle and M. Parasol, J. Chem. Phys, 20, 1487 (1952).

5 R. C. Lord and R. E. Merrifield, J. Chem. Phys. 21, 166 (1953).

$6 \mathrm{~S}$. Mizushima $e^{t}$ al., J. Am. Chem. Soc. 72, 3490 (1950)

7 S. Mizushima el al., J. Am. Chem. Soc. 75, 1863 (1953)

R. D. B. Fraser and W. C. Price, Nature 170, 490 (1952).

\section{Absorption Coefficients of Nitric Oxide in the Vacuum Ultraviolet*}

H. SUN AND G. L. WEISSLER

Department of Physics, University of Southern California,

(Received April 25, 1955)

$\mathrm{P}^{\mathrm{T}}$

RELIMINARY results of the absolute absorption of light in NO have been obtained between $374 \mathrm{~A}$ and $1300 \mathrm{~A}$ from photometric measurements of 60 light source emission lines (Fig. 1 and Table I). The coefficients $\mu$, in units of $\mathrm{cm}^{-1}$ at NTP, are defined by the relation $I=I_{0} \exp (-\mu x)$, and the techniques used were essentially those described in earlier papers ${ }^{1}$ for a grazing incidence vacuum spectrograph. The impurities of NO were stated by the manufacturer (Matheson Company) to be nitrogen and its higher oxides, and it was attempted to freeze out the latter by passing the continuously flowing gas through alcohol cold traps $\left(-110^{\circ} \mathrm{C}\right)$. Because of the fact that the absorption

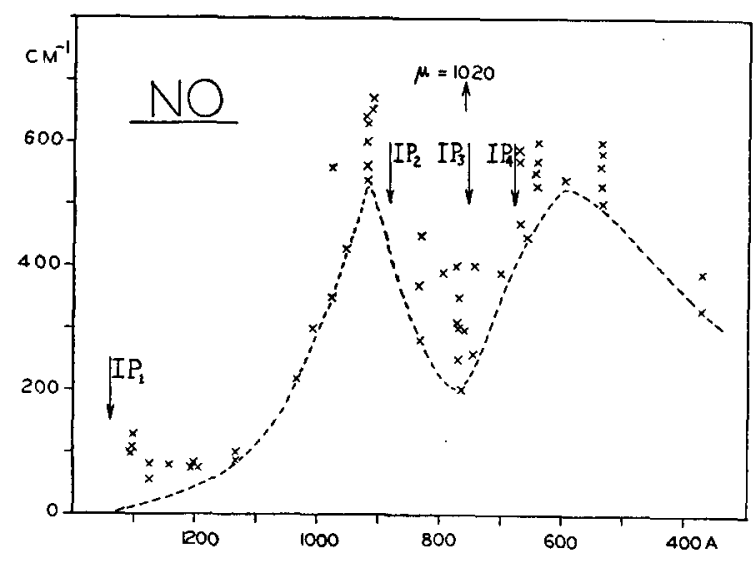

FIG. 1. Absorption coefficients in NO.

coefficients of most gases in their ionization continua are of about the same order of magnitude, it was assumed that the observed absorption in the NO continuum was probably not seriously falsified by any remaining impurities. This received further support from the fact that Zelikoff et al. ${ }^{2}$ reported a broad absorption region (half-width about $55 \mathrm{~A}$ ) in $\mathrm{N}_{2} \mathrm{O}$ with a peak of $2465 \mathrm{~cm}^{-1}$ at $1285 \mathrm{~A}$, whereas the measurements for $\mathrm{NO}$ at $1276 \mathrm{~A}$ and $1302 \mathrm{~A}$ yielded values of $\mu=81 \mathrm{~cm}^{-1}$ and $130 \mathrm{~cm}^{-1}$, respectively.

Previous NO results obtained by $\mathrm{Marmo}^{3}$ and Watanabe between $1100 \mathrm{~A}$ and $2300 \mathrm{~A}$ agree reasonably well with those presented here in the region where overlapping occurred. It should be kept in mind, however, that all those coefficients which fall into resonance bands with well-delineated structure can only give an indication of the magnitude of the absorption there, except for those values which lie within a diffuse band or within dissociation and ionization continua and can therefore be expected to be more accurate. The region from $680 \mathrm{~A}$ towards longer wavelengths is well populated with bands which have been classified by Tanaka ${ }^{5}$ and others into Rydberg and non-Rydberg progressions, and his series limits are indicated by arrows in Fig. 1. This band structure is also apparent in the figure, where adjacent coefficients show widely different values such as $\mu=1020 \mathrm{~cm}^{-1}$ at $764.357 \mathrm{~A}$ and $\mu=200 \mathrm{~cm}^{-1}$ at $765.140 \mathrm{~A}$.

The value of the continuum below $1300 \mathrm{~A}$ may be estimated by connecting together with a line the lowest coefficients, and the

TABLE I. Absorption coefficients $(\mu)$ of NO.

\begin{tabular}{|c|c|c|c|}
\hline$\lambda(\mathrm{A})$ & $\mu\left(\mathrm{cm}^{-1}\right)$ & $\lambda(\mathrm{A})$ & $\mu\left(\mathrm{cm}^{-1}\right)$ \\
\hline 1306.038 O I & 100 & 796.661 O II & 390 \\
\hline $1304.864 \bigcirc \mathrm{O}$ & 110 & 775.957 O II & 400 \\
\hline $1302.1920 \mathrm{I}$ & 130 & $772.975 \mathrm{~N}$ III & 310 \\
\hline $1276.18 \mathrm{~N} \mathrm{II}$ & 81 & $772.385 \mathrm{~N}$ III & 300 \\
\hline $1276.06 \mathrm{~N} \mathrm{II}$ & 56 & $771.901 \mathrm{~N}$ III & 250 \\
\hline $1243.297 \mathrm{~N}$ II & 82 & $771.544 \mathrm{~N}$ III & 350 \\
\hline $1200.706 \mathrm{~N} \mathrm{I}$ & 74 & $765.140 \mathrm{~N} \mathrm{IV}$ & 200 \\
\hline 1200.22 N I & 82 & 764.357 N III & 1020 \\
\hline $1199.527 \mathrm{~N} \mathrm{I}$ & 74 & $763.340 \mathrm{~N}$ III & 300 \\
\hline $1134.98 \mathrm{~N} \mathrm{I}$ & 84 & $746.976 \mathrm{~N}$ II & 260 \\
\hline $1134.419 \mathrm{~N} \mathrm{I}$ & 100 & $745.836 \mathrm{~N}$ II & 400 \\
\hline $1037.332 \mathrm{C} \mathrm{II}$ & 220 & 703.805 O III & 390 \\
\hline $1037.020 \mathrm{C}$ II & 220 & 702.899 O III & 390 \\
\hline $1006.051 \mathrm{~N} \mathrm{II}$ & 300 & 702.332 O III & 390 \\
\hline $979.919 \mathrm{~N}$ III & 350 & $673.768 \mathrm{O}$ II & 590 \\
\hline $977.020 \mathrm{C}$ III & 560 & 672.948 O II & 570 \\
\hline $955.335 \mathrm{~N}$ IV & 430 & $671.397 \mathrm{~N}$ II & 470 \\
\hline $924.274 \mathrm{~N}$ IV & 640 & $660.280 \mathrm{~N}$ II & 450 \\
\hline $923.669 \mathrm{~N}$ IV & 630 & $645.167 \mathrm{~N}$ II & 550 \\
\hline $923.211 \mathrm{~N}$ IV & 600 & $644.825 \mathrm{~N} I \mathrm{I}$ & 570 \\
\hline $923.045 \mathrm{~N}$ IV & 560 & $644.621 \mathrm{~N}$ II & 600 \\
\hline $922.507 \mathrm{~N}$ IV & 540 & 644.148 o II & 530 \\
\hline $916.708 \mathrm{~N}$ II & 670 & 599.589 O III & 540 \\
\hline $916.01 \mathrm{~N} I I$ & 650 & 539.853 O II & 560 \\
\hline 915.96 N II & 670 & 539.547 O II & 530 \\
\hline 835.293 O III & 370 & 539.086 O II & 600 \\
\hline 834.467 O III & 370 & 538.318 O II & 500 \\
\hline 833.749 O III & 280 & 537.830 O II & 589 \\
\hline 833.332 O II & 450 & 374.330 O III & 390 \\
\hline 832.930 O III & 280 & 374.075 O III & 340 \\
\hline
\end{tabular}

